\title{
Effectiveness of Computer Assisted Problem based Learning in Chemistry for Enhancing Thinking Skills among Secondary School Students
}

\author{
Rajeswari K \\ Department of Master of Eduction, Government College of Teacher Education, Affiliated to University of Kerala, Kerala 695014, \\ India
}

\begin{abstract}
Experiencing problems that challenges science and the thought, habits of mind and actions associated with trying to solve them is one of the best ways of learning Chemistry. This impels opportunities for authentic, inquiry based learning. PBL (problem based learning) is a student centered pedagogy in which students learn about a subject through the experience of problem solving. The goals of PBL are to help the students develop flexible knowledge, effective problem solving skills, self-directed learning, effective collaborative skills and intrinsic motivation. CAPBL (computer assisted problem based learning) has been created to expand the boundaries of the creativity and the creativity of students beyond the four walls of the classroom. In the present study the investigator tested the effectiveness of the CAPBL material in Chemistry for enhancing thinking skills among secondary school students. The sample consisted of 100 secondary school students. The study revealed that the CAPBL material in Chemistry is effective in enhancing thinking skills such as critical thinking, creativity and problem solving.
\end{abstract}

Key words: CAPBL, thinking skills, creativity, problem solving skills.

\section{Introduction}

Science has been characterized as a body of knowledge obtained by scientists. Science is dynamic in its nature changes taking place are both substantial and peripheral. Scientific information is constantly being rearranged and reoriented in the light of latest developments. Thus the dynamic nature of science is to be made clear to students to enable them to use this knowledge in their daily life. Technology has helped to expand the scope and depth of education across borders. Technological application has offered new resources for learning [1]. Merely introducing technology to the educational process is not enough. The thoughtful pedagogical use of technology requires the development of a complex, form of

\footnotetext{
*Corresponding author: Rajeswari $\mathrm{K}$, reader in charge of department of master of education, research fields: science education, non-formal education, learning difficulties, remedial instruction, and innovative practices in teaching and assessment. E-mail: drrajigcte@gmail.com.
}

knowledge that we call TPCK (technological pedagogical content knowledge). In doing so the merging of three main components of learning environment such as content, pedagogy and technology. The attempt of TPCK was to encourage teachers to design project in which the applied pedagogical content knowledge (pedagogy) and technological knowledge of various information communication technologies tools (technology) to create a subject specific lesson package (content).

\section{Learning of Chemistry in the Frame Work of TPCK}

One of the purposes of teaching Chemistry in school is to bring Chemistry to life. It enables students to grasp ideas systematically and further apply it to solve real world problems. The best way for students to learn Chemistry is to experience problems that challenge science and the thought, habits of mind and actions associated with trying to solve them [2]. This 
impels opportunities for authentic, inquiry based learning. PBL is a powerful vehicle in which a real world problem becomes a context for students to investigate in depth, what they need to know and what they want to know [1].

\section{CAPBL (Computer Assisted Problem Based Learning)}

PBL (problem based learning) is a student centered pedagogy in which students learn about a subject through the experience of problem solving. The goals of PBL are to help the students develop flexible knowledge, effective problem solving skills, self-directed learning, effective collaborative skills and intrinsic motivation. Problem based learning is a style of active learning.

Computer assisted instruction represents a teaching tool that involves the use of computer programme or programs to facilitate the education of a group of student. Its major goal is to provide practical assistance to interactive programmes that teach effectively. An integration of IT (information technology) enabled technology with problem based learning leads to introduction of yet another strategy which makes learning more productive [3]. CAPBL has been created to expand the boundaries of the creativity and the creativity of students beyond the four walls of the classroom.

\section{Importance of Thinking Skills}

Thinking skills can be defined as patterns of thinking that help learners go beyond the mere recall of of information and enable them to explore and make sense of their world, to reason and problem solve, as well as to plan, create and invent. Although we are all born with a capability to think, there is ample evidence that we can learn to think more skillfully. Thinking skills refer to processes of thinking and learning in a wide range of contexts, not just in schools [2]. Developing thinking skills is a part of learning to learn. Developing thinking skills enable learners to gain deeper understanding of topics, to be more critical about evidence to think flexibly and to make reasoned judgments and decision rather than jumping to be drawn on when they encounter new situation [4]. There are many strategies and methods for the enhancement of thinking skills among learners. Project method, PBL, computer assisted instruction, debates, collaborative learning, brain storming sessions, Buzzer techniques, etc., are some among them [2]. For the study the investigator selected CAPBL to enhance thinking skills among secondary school students [1].

\section{Need and Significance of the Study}

It is a great fact that science teaching and learning is a complex task. The efforts at reforming science teaching have often been restricted in scope and have focused mainly on updating the science content in text books. School education is the crucial factor that decides the future of the nation. The challenges and problems of the contemporary world can be met only if we develop a progressive and comprehensive system. It would give opportunities to the learners to think critically and develop insight into these problems and issues. It is doubtful whether the instructional strategies employed in schools are enough to develop the thinking skills of the students [5]. It is the responsibility of the teachers and authorities to provide facilities for the students to think efficiently.

Many studies proved that learning will be effective by introducing participatory approaches in classroom teaching and learning. In the participatory approaches the teacher and the students equally share the responsibility of learning. In participatory approaches students are actively participating in the teaching-learning process.

One of the major criticisms on computer assisted learning is the inactive involvement of learners and lack of opportunity for the development of social skills. In this study due emphasis was given for the 
participation of students and maximum involvement of the learners in teaching learning process [6]. By CAPBL strategy, there will be an enhancement not only in the thinking skills of the students, but also in the technological skills, social skills, research skills and interpersonal skills [7]. It could help the teachers and curriculum planners to experiment on new ways of teaching, in the new era of technological advancement to make learning Chemistry more exciting and interesting.

\section{Statement of the Problem}

The study of Chemistry becomes interesting and effective if it is transacted in a better way such that the learner personally engages in the process of Science. Due emphasis has to be given on how to teach or learn rather than what to teach or learn [5]. Since the main intention is to develop thinking skills among students, the investigator selected problem based learning incorporated with computer assisted learning. Hence the study is stated as, effectiveness of CAPBL in Physic for developing thinking skills among secondary schools students.

\section{Objectives of the Study}

The major objectives of the study are:

- To prepare and validate a CAPBL material in Chemistry for the topic daily Chemistry for the secondary school students,

- To test the effectiveness of the CAPBL material for developing thinking skills among secondary school students by comparing the pre-test and immediate post-test scores of total sample,

- To test the effectiveness of the CAPBL material in developing thinking skills among secondary school students by comparing the pre-test and immediate post-test thinking skill test scores such as critical thinking, creative thinking and problem solving,

- To test the effectiveness of the CAPBL material in developing thinking skills among secondary school students by comparing the immediate post-test and delayed post-test thinking skill test scores for total sample.

\section{Hypotheses of the Study}

The CAPBL is effective in developing thinking skills among secondary school students.

\section{Methodology in Brief}

The present study aimed at finding out the effectiveness of computer assisted problem based on learning in Chemistry for developing thinking skills among secondary school students.

The details regarding the method adopted for collecting data, tools and materials used for the study, statistical techniques employed for analysis of data are given below:

\section{Method Selected for the Study}

The pre- and post-test single group experimental design was adopted for the study.

\section{Sample Selected for the Study}

The sample consisted of 100 students studying in standards IX.

\section{Tools and Materials Used for the Study}

The major tools and materials used for the study are:

- CAPBL material on energy management

- Rating scale for experts for validation

- Thinking skill test in Chemistry

The above tools and materials were prepared by the investigator CAPBL material.

The material comprises of CAPBL material in Chemistry prepared by the investigator and CAPBL material in Chemistry prepared by the students. The details are given below:

CAPBL Material in Chemistry Prepared by the Investigator

The unit plan, lesson plans, and supply materials including a PowerPoint presentation on daily Chemistry, questionnaire and survey form for conducting survey on use of soft drinks, notice on the importance of using natural drinks over soft drinks, 
newsletter, posters on the ill effects of using artificial sweeteners and preservatives, an interview schedule for doctors, chemists and scientists.

\section{CAPBL Material Prepared by the Students}

The students prepared learning materials on the unity chemistry for enhancing thinking skills among students with the assistance of the teacher, as a facilitator. The materials prepared by the students in each group includes a power point presentation, questionnaire and survey form for conducting survey, notice, newsletter, posters and interview schedule. (developed by the students with the assistance of the investigator).

\section{Thinking Skill Test in Chemistry}

The test comprises of the thinking skills such as critical thinking skill, creative thinking skill and problem solving skills based on the unit daily Chemistry. The same test was used as the pre- and post-test.

Statistical techniques used for the study: percentage analysis, calculation of arithmetic mean and standard deviation and test of significance of difference between means, major findings of the study.

The major findings drawn from the study are: The percentage analysis made for the responses collected from teachers and experts regarding the material prepared revealed that a great majority (98\%) of experts and teachers reported that the material is practicable in a normal classroom. They also reported that it is suitable in enhancing the thinking skills of students. It is followed by simple to comprehend, effective in minimizing the stress among students, suitable for developing interest and relevance of the material.

In terms of mean scores in thinking skill test in Chemistry: The CAPBL material in Chemistry was effective in enhancing thinking skills among secondary school students. This conclusion is based on the test of significance between mean pre- and post-test scores $(\mathrm{t}$ value $=3.69$, significant at 0.01 level).
There exists significant difference between the mean pre- and post-test scores for the thinking skill critical thinking $(\mathrm{t}$ value $=3.20$, significant at 0.01 level).

There exists significant difference between the mean pre- and post-test scores for the thinking skill-creative thinking $(\mathrm{t}$ value $=4.55$, significant at 0.01 level).

There exists significant difference between the mean pre- and post-test scores for the thinking skill problem solving $(\mathrm{t}$ value $=4.53$, significant at 0.01 level).

There exists no significant difference between the mean immediate post-test and delayed post-test scores for the thinking skill $(\mathrm{t}$ value $=1.60)$. This may be due to the treatment given to the experimental group and the effectiveness of the CAPBL material.

Hence the CAPBL material in Chemistry on the topic every day Chemistry is effective in developing thinking skills such as critical thinking, creative thinking and problem solving among students.

\section{Discussion of Results}

From the above findings it can be concluded that CAPBL is found to be effective in enhancing thinking skills among students at secondary level. The comparison of the mean scores of component skills between pre-test and immediate post-test of the experimental group reveals that CAPBL is effective in developing the three component skills such as critical thinking, creative thinking and problem solving.

The results of the present study have a very significant value in the field of science education and hence the present study has a number of implications. CAPBL is found to be effective in enhancing thinking skills especially critical thinking, creativity and problem solving among secondary schools students. In addition to this CAPBL helps in enhancing technological skills of the students by means of PowerPoint preparation, newsletter and notice preparation which is very essential in this modern world, it also helps in the 
Thinking Skills among Secondary School Students

development of research skills, inquiry skills, and social skills through the surveys, field trips, nature study etc., which are essential part of this learning. Learning by searching internet, referring magazines preparing story boards, interviewing individuals etc. arouse the curiosity and appeal the interest of the learners.

\section{References}

[1] Debbie, C., Jennifer, D., Robert, H., Judge, J. Y., Judi\&Kuni, P. 2004. Intel Teach programme, X-elerted professional development for Integration of Technology in Teacher Education (XPDITTE). Pre-service edition, Martinez Unified: Intel Corporation.

[2] http://wikieducator.org/Problem Based learning.

[3] Mohan, R. 2007. Innovative Science Teaching. New Delhi: Prentice Hall of India Pvt. Ltd.

[4] http://wikieducator.org/thinking.

[5] Jayamani, A. 1991. "A CAI Package in Physics for Class XI Studsnents.” M.Ed Disseration,Univesity of Kerala.

[6] Jisha. 2006. “A Comparative Study on CAI and Activity Method in Learning the Morphology and Medical Importance of Dashapushpas at the Highersecondary Level.” M. Ed dissertation, University of Kerala.

[7] http://wikieducator.org/life skills. 